\title{
COVID-19 AS A CATALYST FOR THE TRANSFORMATION OF CONTRACTUAL AND ENFORCEMENT PRACTICES ${ }^{1}$
}

\author{
Yuliya A. Tymchuk \\ Volgograd State University, Volgograd, Russian Federation
}

Introduction: the article provides an overview of the impact of the coronavirus pandemic (COVID-19) on treaty and enforcement practices. The most common methods of conclusion of civil-law contracts, as well as problems of fulfillment of contractual conditions, which arose against the background of spread of coronavirus infection, are considered. Legislative innovations were analysed, which led to a change in the procedure for the execution of certain types of civil law contracts, court practice, in which the legal position of the parties was based on arguments about the coronavirus pandemic. Methods: this study used both public science (dialectical method of cognition, analysis, synthesis, formal-logical method, prognostic, etc.) and private science methods (formal-legal, method of legal interpretation, etc.). Results: it is justified to increase the demand for digital technologies in the context of measures taken by the state to prevent the spread of coronavirus infection. New trends in contract practice have been identified and considered. The possibilities of legal qualification of coronavirus as a force majeure, the circumstance that makes it impossible to fulfill obligations, a significant change of circumstances, including taking into account the available judicial practice at the time of writing, have been determined. Online settlement of disputes arising from non-performance of contractual obligations has been proved to be useful. Conclusions: based on the results of the study, the interdependence between the level of introduction of digital technologies into public administration, the judicial system, the economic activity of business entities and the possibility of adaptation to the conduct of current activities in these spheres in the context of the spread of the crown virus has been determined.

Key words: legal fact, coronavirus, electronic commerce, contractual practice, force majeure, significant change of circumstances, judicial practice.

Citation. Tymchuk Yu.A. COVID-19 as a Catalyst for the Transformation of Contractual and Enforcement Practices. Legal Concept, 2020, vol. 19, no. 3, pp. 31-40. (in Russian). DOI: https://doi.org/10.15688/lc.jvolsu.2020.3.4

УДК 347.1

Дата поступления статьи: 01.07.2020

ББК 67.404

Дата принятия статьи: 20.07.2020

\section{COVID-19 КАК КАТАЛИЗАТОР ТРАНСФОРМАЦИИ ДОГОВОРНОЙ И ПРАВОПРИМЕНИТЕЛЬНОЙ ПРАКТИКИ ${ }^{1}$}

\author{
Юлия Александровна Тымчук \\ Волгоградский государственный университет, г. Волгоград, Российская Федерация
}

\begin{abstract}
Введение: в статье представлен обзор влияния пандемии коронавируса (COVID-19) на договорную и правоприменительную практику. Рассмотрены наиболее распространенные способы заключения гражданско-правовых договоров, а также проблемы исполнения договорных условий, возникшие на фоне распространения коронавирусной инфекции. Проанализированы законодательные нововведения, обусловившие изменение порядка исполнения отдельных видов гражданско-правовых договоров, судебная практика, в которой правовая позиция сторон основывалась на аргументах о пандемии коронавируса. Методы: в настоящем исследовании были исi пользованы как общенаучные (диалектический метод познания, анализ, синтез, формально-логический, прогностический методы и др.), так и частнонаучные методы (формально-юридический, метод юридического толкования и др.). Результаты: обосновано повышение востребованности цифровых технологий в условиях предпринятых государством мер по предотвращению распространения коронавирусной инфекции. Выявлены и рассмотрены новые тенденции договорной практики. Определены возможности правовой квалификации коронавируса в (2) качестве непреодолимой силы, обстоятельства, обусловливающего невозможность исполнения обязательств,
\end{abstract}


существенного изменения обстоятельств, в том числе с учетом имеющейся на момент написания работы судебной практики. Доказана целесообразность онлайн-урегулирования споров, возникающих в связи с неисполнением договорных обязательств. Выводы: по итогам проведенного исследования определена взаимозависимость между уровнем внедрения цифровых технологий в государственное управление, судебную систему, хозяйственную деятельность субъектов предпринимательской деятельности и возможностью адаптации к ведению текущей деятельности в данных сферах в условиях распространения коронавируса.

Ключевые слова: юридический факт, коронавирус, электронная коммерция, договорная практика, непреодолимая сила, существенное изменение обстоятельств, судебная практика.

Цитирование. Тымчук Ю. А. COVID-19 как катализатор трансформации договорной и правоприменительной практики // Legal Concept = Правовая парадигма. - 2020. - T. 19, № 3. - C. 31-40. - DOI: https://doi.org/ 10.15688/lc.jvolsu.2020.3.4

\section{Введение}

В юридической доктрине возникновение, изменение и прекращение правоотношений принято связывать с юридическими фактами, которые классифицируются на действия и события [2, с. $624 ; 7$, с. $405 ; 8$, с. 244]. К последним относятся факты реальной действительности, развивающиеся независимо от воли субъектов. Сегодня одним из таких серьезных событий, которое существенно влияет как на реализацию и осуществление прав и обязанностей физических и юридических лиц (на всех уровнях), так и на нормальное развитие политической, экономической и правовой сфер, выступает вспышка коронавирусного заболевания COVID-19, объявленного Всемирной организацией здравоохранения пандемией [1]. В России был принят ряд мер для предотвращения распространения коронавирусной инфекции и поддержки отечественной экономики. Кроме того, поскольку, согласно ст. 72 Конституции РФ, осуществление мер по борьбе с эпидемиями относится к вопросам совместного ведения в ряде субъектов РФ, на основании положений специальных федеральных законов, подзаконных нормативных актов в ряде субъектов РФ было принято решение о введении режима повышенной готовности [18]. Обозначенное абсолютное юридическое событие закономерно повлияло на договорную и правоприменительную практику.

\section{Тенденции развития договорной практики}

\section{в условиях пандемии коронавируса}

Анализ договорной практики субъектов гражданского оборота, складывающейся в но- вых условиях, позволяет выделить ряд тенденций ее развития.

Прежде всего, пандемия коронавируса стала катализатором углубления процессов цифровизации гражданского оборота. Это проявляется в том, что его субъекты, осознавая объективную необходимость в недопущении распространения новой инфекции (в основном посредством ограничения очных контактов с другими людьми) и принимая во внимание обязательные превентивно-профилактические меры, вводимые уполномоченными органами (временное ограничение деятельности многих субъектов предпринимательской деятельности, режим самоизоляции граждан и пр. [17; 20]) как в целях удовлетворения обычных бытовых потребностей посредством заключения мелких бытовых сделок, так и ведения текущей хозяйственной деятельности юридическими лицами и индивидуальными предпринимателями, все чаще обращаются к цифровым инструментам.

Наиболее ярким примером вышеизложенного является такой сегмент электронной коммерции, как В2С (бизнес - потребитель), одним из юридических проявлений которого выступают заключаемые онлайн-контракты. На основе анализа веб-сайтов ряда интернетмагазинов [3; 16; 19] (в частности, условий продажи товаров, способов доставки, порядка заключения договоров на веб-сайте) возможно прийти к выводу о том, что такое юридическое событие, как вспышка коронавирусной инфекции, привело к росту числа заключаемых между продавцами и покупателями-потребителями онлайн-контрактов на веб-сайтах магазинов в сети Интернет [11], а именно договоров розничной купли-продажи на условиях публичной оферты, в том числе с усло- 
вием о бесконтактной доставке (ст. 499 ГК РФ). При этом способом заключения таких онлайн-контрактов выступает click-wrap. В качестве дополнительного обстоятельства, повышающего привлекательность заключения онлайн-контрактов в рассматриваемом сегменте электронной коммерции, выступают более длительные сроки возврата/обмена [10] непродовольственных товаров, введенные многими ритейлерами, реализовавшими положения п. 1 ст. 502 ГК РФ. За рубежом наблюдаются аналогичные тенденции [26].

Соответственно, вспышка коронавирусной инфекции в рассматриваемом контексте является фактором, усиливающим влияние цифрового элемента как признака, характеризующего складывающиеся договорные связи [9, c. 22].

Примечательно, что вспышка коронавирусной инфекции привела и к пересмотру подхода отечественного законодателя к розничной продаже таких особых товаров, как лекарственные препараты [24].

Следующей тенденцией договорной практики в новых условиях выступает корректировка порядка и способов исполнения отдельных видов гражданско-правовых договоров. В частности, поскольку вспышка COVID-19 привела к ряду неблагоприятных экономических последствий для субъектов предпринимательской деятельности, государство в целях поддержки бизнеса пересмотрело порядок исполнения договоров аренды государственного или муниципального недвижимого имущества, заключенных до возникновения пандемии. В частности, в третьем чтении принят законопроект № 931192-7, обязывающий арендодателя предоставить по обращению арендатора отсрочку уплаты арендной платы, предусмотренной в 2020 году.

Другим ярким примером служит реализация договоров об образовании в высших учебных заведениях, в которых во исполнение Приказа Минобрнауки РФ от 14 марта 2020 г. № 397 организованы мероприятия по проведению контактной работы преподавателей и студентов исключительно в электронной информационно-образовательной среде, обеспечивающей удаленное взаимодействие обучающихся и преподавателей. Соответственно, возможно констатировать изменение порядка предоставления образовательных услуг, в том числе в рамках заключенных возмездных договоров с обучающимися. Вместе с тем, учитывая, что в большинстве образовательных организаций, подведомственных министерству, разработаны типовые формы договоров об образовании (об оказании образовательных услуг), в которых обязательства университета по договору сформулированы максимально широко, следует признать, что внесение изменений в такие договоры посредством заключения дополнительных соглашений не потребуется.

Представляется, что наиболее существенное влияние с позиции договорного права коронавирусная инфекция оказала на надлежащее исполнение договорных условий, содержащихся в договорах как осложненных [5, c. 44], так и не осложненных иностранным элементом.

Отечественной цивилистической доктрине, законодательству и правоприменительной практике известны несколько гражданско-правовых институтов, которые в рассматриваемых условиях приобретают особую актуальность. Речь идет об институтах: 1) непреодолимой силы (форс-мажор) - п. 3 ст. 401 ГК РФ; 2) невозможности исполнения обязательств ст. 416, 417 ГК РФ; 3) существенного изменения обстоятельств - ст. 451 ГК РФ.

Рассмотрим подробнее перспективы применения норм каждого института в контексте проблемы исполнения гражданско-правовых договоров.

В российском законодательстве и судебной практике выработаны критерии, позволяющие отнести то или иное юридическое событие к форс-мажорным. Среди них критерии чрезвычайности и непредотвратимости. Опираясь на данные подходы, позиция Торгово-промышленной палаты РФ, а также властей отдельных субъектов РФ и муниципальных образований сводится к признанию коронавируса форс-мажорным обстоятельством для исполнения договоров, что, собственно, исключает ответственность за нарушение обязательств.

Например, в Указе Мэра Москвы от 5 марта 2020 г. № 12-УМ «О введении режима повышенной готовности» [23] прямо указано, что распространение новой коронавирус- 
ной инфекции (2019-nCoV) является обстоятельством непреодолимой силы.

Полагаем, что при анализе данного нормативного акта и перспектив его практического применения, в том числе в ходе судебных разбирательств, необходимо учитывать его подзаконный характер, а также действие в пространстве. Кроме того, по смыслу п. 3 ст. 401 ГК РФ невозможность исполнения обязательств в результате непреодолимой силы подлежит доказыванию. В связи с этим представляется, что квалификация конкретных обстоятельств как непреодолимой силы является компетенцией судебных органов, а не органов исполнительной власти и, исходя из положений ст. 3 ГК РФ, суд не может быть связан выводами, содержащимися в обозначенном указе. Кроме того, в зависимости от особенностей и обстоятельств конкретного дела возможно применить и положения ст. 451 ГК РФ о существенном изменении обстоятельств.

Что касается внешнеторговых сделок, то решение вопроса об отнесении коронавирусной инфекции к форс-мажорным обстоятельствам также будет зависеть как от условий договоpa, так и от права, применимого к договору. При этом одним из способов доказывания наступления такого обстоятельства в рамках внешнеторговой сделки является получение сертификата Торгово-промышленной палаты России о форс-мажоре, который с 26 марта 2020 г. выдается безвозмездно [25]. Несмотря на то что Положением о порядке свидетельствования Торгово-промышленной палатой Российской Федерации обстоятельств непреодолимой силы (форс-мажора) предусмотрена выдача сертификатов о форс-мажоре только по внешнеторговым сделкам, ТПП РФ анонсировала выдачу таких сертификатов и для российских юридических лиц, заключивших договор, который не осложнен иностранным элементом.

Следует отметить, что в подобных условиях в связи с объективной потребностью в урегулировании споров, которые неизбежно могут возникнуть между контрагентами в связи с ненадлежащим исполнением обязательств, целесообразно, на наш взгляд, обращение к альтернативным способам урегулирования споров, а именно - к онлайн-урегулированию (Online dispute resolution - ODR) [6, c. $31 ; 27$, p. 140].
Рассматривая концепцию о квалификации коронавирусной инфекции как существенного изменения обстоятельств (ст. 451 ГК РФ), следует отметить, что по смыслу позиции Ростуризма [4] ее применение в совокупности с положениями ст. 781 ГК РФ, ст. 10 Федерального закона от 24 ноября 1996 г. № 132-Ф3 «Об основах туристской деятельности в Российской Федерации» возможно. Кроме того, концепция существенного изменения обстоятельств в контексте распространения коронавирусной инфекции применяется к договорам оказания услуг по организации и проведению массовых культурно-зрелищных мероприятий [22] и др.

Что касается возможности квалификации коронавирусной инфекции с позиции ст. 416, 417 ГК РФ как обстоятельства, исключающего возможность исполнения обязательств, то, на наш взгляд, выбор такого подхода будет обусловлен спецификой конкретного дела. Например, в случае, предусмотренном ст. 417 ГК РФ, издание акта органа власти о запрете въезда или выезда с территории государства, запрете перевозок и пр. в целях недопущения распространения коронавирусной инфекции может являться препятствием для исполнения отдельных видов договоров (в частности, поставки, оказания услуг и пр.), для которых место исполнения сделки или личность исполнителя имеет решающее значение.

\section{Вопросы квалификации пандемии коронавируса в судебной практике}

Обращение к имеющейся на момент написания настоящей работы судебной практике (преимущественно арбитражных судов) позволило обнаружить несколько арбитражных дел, в которых стороны пытались ссылаться на эпидемиологическую ситуацию, связанную с распространением коронавируса.

Так, в одном из дел общество, в отношении которого было открыто конкурсное производство, обратилось в суд с заявлением о намерении погасить требования об уплате обязательных платежей, которое было удовлетворено. Судом был установлен срок для погашения задолженности, составляющий 30 дней. По истечении данного срока состоя- 
лось судебное заседание, где рассматривались итоги погашения. Должник в обозначенный срок задолженность не погасил и заявил ходатайство о продлении срока для оплаты и отложении судебного заседания, в обоснование которого ссылался на факт отсутствия возможности выполнения обязательств в силу возникновения обстоятельств непреодолимой силы, к которым относится эпидемия коронавируса в Китае. Основным видом деятельности должника выступает лесопереработка древесины, крупнейшим покупателем которой выступает Китай. Поскольку из-за распространения коронавируса была приостановлена деятельность ряда китайских предприятий, в том числе произведение расчетов за поставленную продукцию, у организации возникли убытки, наличие которых, при явном намерении погасить задолженность, не позволили в срок исполнить определение суда. Данные доводы, как мы полагаем, были приняты во внимание судом, несмотря на то что в судебном акте сведений об их оценке не содержится. Ходатайство должника об отложении судебного заседания было удовлетворено, что фактически предоставляет ему дополнительное время для погашения задолженности [13].

Распространение коронавируса попытались использовать и для обоснования заявленного ходатайства о принятии обеспечительных мер в виде приостановления действия акта уполномоченного органа, которым в связи с выявленными нарушениями приостанавливалось действие лицензии заявителя на производство и оборот этилового спирта, алкогольной и спиртосодержащей продукции. Так, заявитель ссылался на необходимость принятия обеспечительных мер для возобновления предпринимательской деятельности, осуществление которой имеет важное значение в условиях пандемии коронавируса, так как спирт и спиртосодержащая продукция, имеющиеся в распоряжении заявителя, могут быть использованы для производства дезинфицирующих средств, потребность в использовании которых крайне высока в сложившихся обстоятельствах.

Суд оценил данные доводы и пришел к выводу о том, что заявителем не обоснована и не подтверждена высокая значимость его продукции в условиях пандемии коронавиру- са (отсутствуют доказательства уникальности продукции, потребности в формировании мобилизационного резерва, установленной уполномоченными органами и пр.), а выпуск и реализация заявителем спиртосодержащей продукции не входит в установленный уполномоченными органами перечень мер по борьбе с распространением коронавируса. В связи с этим вспышка коронавируса не препятствует исполнению обязательных требований Федерального закона от 22 ноября 1995 г. № 171-Ф3, не может расцениваться как обстоятельство чрезвычайного характера, являющееся основанием для предоставления обществу преференции на нарушения [12].

Однако в другом деле, напротив, доводы о вспышке коронавирусной инфекции были учтены судом при вынесении определения о принятии обеспечительных мер в виде приостановления действия актов налоговых органов о доначислении налогов [14].

Полагаем, что в ходе принятия решений об удовлетворении таких ходатайств судом будут учтены как сфера деятельности конкретной организации, так и соотношение обеспечительной меры с принятыми государством способами поддержки бизнеса.

Следует отметить, что, к сожалению, немногочисленность и противоречивость имеющейся на момент написания настоящей работы судебной практики не позволяют сформулировать конкретные тенденции ее развития в части квалификации коронавируса как форс-мажора, обстоятельства, обусловливающего невозможность исполнения обязательств, или существенного изменения обстоятельств. При этом определенная ясность в вопросе правовой квалификации коронавируса появилась после выхода первого и второго Обзоров по отдельным вопросам судебной практики, связанным с применением законодательства и мер по противодействию распространению на территории Российской Федерации новой коронавирусной инфекции (COVID-19), утвержденных Президиумом ВC РФ 21 и 30 апреля 2020 г. соответственно. Так, по смыслу обзоров коронавирус не является универсальным обстоятельством непреодолимой силы, а решение вопроса о его правовой квалификации будет приниматься с учетом всех обстоятельств дела. 


\section{Выводы}

Коронавирус оказал существенное влияние на динамику гражданского оборота, выражением которого стали различные гражданско-правовые сделки. В свою очередь, последние выступают традиционным атрибутом как предпринимательской деятельности, так и обычной жизнедеятельности физических лиц, удовлетворяющих повседневные бытовые потребности.

Как показало проведенное исследование, основными тенденциями развития договорной практики, возникшими на фоне пандемии коронавируса, выступают:

- рост числа заключаемых онлайн-контрактов, особенно в таком сегменте электронной коммерции, как В2С (бизнес - потребитель). Такие онлайн-контракты заключаются способом click-wrap между продавцами и покупателями-потребителями на веб-сайтах магазинов в сети Интернет и могут быть по своей правовой природе отнесены к договорам розничной купли-продажи на условиях публичной оферты, в том числе с условием о бесконтактной доставке (ст. 499 ГК РФ);

- корректировка порядка и способов исполнения отдельных видов гражданско-правовых договоров, среди которых: договоры аренды государственного или муниципального недвижимого имущества, заключенные до возникновения пандемии, договоры об образовании в высших учебных заведениях и др.;

- возникновение проблемы надлежащего исполнения гражданско-правовых договоров, для решения которой следует обратиться к институтам непреодолимой силы, невозможности исполнения обязательств, существенного изменения обстоятельств.

Положительным нововведением с точки зрения квалификации коронавируса как форсмажора выступает анонсированная Торговопромышленной палатой РФ безвозмездная выдача сертификатов о форс-мажоре сторонам не только внешнеторговых сделок, но и внутригосударственных [21]. Вместе с тем до настоящего времени соответствующие изменения не были внесены в Положение о порядке свидетельствования Торгово-промышленной палатой Российской Федерации обстоятельств непреодолимой силы (форс-мажора) [15], что препятствует оперативному получению сертификатов ввиду неясностей процедуры.

В судебной практике подходы к юридической квалификации коронавируса также не сформулированы. Анализ имеющейся на момент написания настоящей работы судебной практики арбитражных судов позволяет сделать вывод о том, что суды крайне осторожно подходят к оценке позиций по делу, в которых стороны ссылаются на коронавирус.

Исследование влияния рассмотренного юридического события на договорную и правоприменительную практику позволяет сделать вывод о том, что востребованность современных цифровых технологий в новых непредвиденных условиях существенно возрастает. Соответственно, возможно признать, что от уровня развития и успеха внедрения цифровых технологий в государственное управление, судебную систему, хозяйственную деятельность субъектов предпринимательской деятельности зависит возможность адаптации последних к ведению текущей деятельности в условиях распространения коронавируса.

\section{ПРИМЕЧАНИЕ}

${ }^{1}$ Исследование выполнено за счет гранта Российского научного фонда (проект № 18-78-10075).

The work was supported by Russian Science Foundation (project № 18-78-10075).

\section{СПИСОК ЛИТЕРАТУРЫ}

1. ВОЗ объявила о начале пандемии COVID-19 // Всемирная организация здравоохранения. - Электрон. текстовые дан. - Режим доступа: http:// www.euro.who.int/ru/health-topics/health-emergencies /coronavirus-covid-19/news/news/2020/3/whoannounces-covid-19-outbreak-a-pandemic (дата обращения: 12.03.2020). - Загл. с экрана.

2. Вопленко, Н. Н. Очерки общей теории права : монография / Н.Н. Вопленко. - Волгоград : Изд-во ВолГУ, 2009. $-898 \mathrm{c}$.

3. Информация // Онлайн-магазин Утконос. Электрон. текстовые дан. - Режим доступа: https:// www.utkonos.ru/doc/info (дата обращения: 20.03.2020). - Загл. с экрана.

4. Информация для туристов на 14.03 .2020 // Федеральное агентство по туризму. - Электрон. текстовые дан. - Режим доступа: https:// 
www.russiatourism.ru/news/16587/ (дата обращения: 22.03.2020). - Загл. с экрана.

5. Иншакова, А. О. Вопросы квалификации внешнеэкономической сделки и правовая специфика некоторых ее видов / А. О. Иншакова // Вестник Волгоградского государственного университета. Серия 5, Юриспруденция. - 2015. - № 2 (27). - С. 37-45.

6. Иншакова, А. О. Цифровые технологии альтернативных методов разрешения споров: зарубежная практика и перспективы применения в России / А. О. Иншакова, Ю. А. Тымчук // Право и управление. XXI век. - 2019. - № 1. - С. 23-31.

7. Матузов, Н. И. Теория государства и права : учебник / Н. И. Матузов, А. В. Малько. - 2-е изд., перераб. и доп. - М. : Юристь, 2009. - 541 с.

8. Морозова, Л. А. Теория государства и права : учебник / Л. А. Морозова. - 4-е изд., перераб. и доп. - М. : Эксмо, 2010. - 480 с.

9. Муратова, О.В.Концепция транснационального потребительского права в современном мире / О. В. Муратова //Lex russica. - 2019. - № 7. - C. 20-28.

10. Обмен и возврат // Mango. - Электрон. текстовые дан. - Режим доступа: https://shop.mango.com/ ru/muz/help/2882.html (дата обращения: 20.03.2020). Загл. с экрана.

11. Онлайн-ритейлеры резко нарастили продажи продуктов и увеличили сроки доставки // Интерфакт. - Электрон. текстовые дан. - Режим доступа: https://www.interfax.ru/russia/699424 (дата обращения: 20.04.2020). - Загл. с экрана.

12. Определение Арбитражного суда Воронежской области об отказе в удовлетворении ходатайства от 19.03.2020 по делу № А14-15204/2019// Картотека арбитражных дел. - Электрон. текстовые дан. - Режим доступа: https://ras.arbitr.ru/Document/ Pdf/0b2b08e3-036b-4c94-b7c1-ba4c2820393b/ 36ea22af-40a9-471e-b94a-c28af4c10b67/\%D0\%901415204-2019_20200319.pdf?isAddStamp=True (дата обращения: 10.04.2020). - Загл. с экрана.

13. Определение Арбитражного суда Иркутской области об отложении судебного разбирательства от 10.03.2020 по делу № А19-10914/2018 // Картотека арбитражных дел. - Электрон. текстовые дан. - Режим доступа: https://ras.arbitr.ru/Document/ Pdf/d813d290-76ef-416e-b135-cd61060bb491/ 68363adc-c5c1-462d-bbfd-308688cfef3a/\%D0\%901910914-2018_20200313.pdf?isAddStamp=True (дата обращения: 15.04.2020). - Загл. с экрана.

14. Определение Арбитражного суда КабардиноБалкарской Республики от 27.03.2020 по делу № А201094/2020 // Картотека арбитражных дел. - Электрон. текстовые дан. - Режим доступа: http://kad.arbitr.ru/ Document/Pdf/c90277aa-0b34-4946-bccc-a1776685a09f/ fad93 f0a-e66f-41e2-8cf0-7a8685d0cc8b/A20-10942020_20200327_Opredelenie.pdf?isAddStamp=True (дата обращения: 26.04.2020). - Загл. с экрана.
15. Положение о порядке свидетельствования Торгово-промышленной палатой Российской Федерации обстоятельств непреодолимой силы (форсмажор) (приложение к постановлению Правления ТПП РФ от 23.12.2015 № 173-14). - Доступ из справ.правовой системы «КонсультантПлюс».

16. Пользовательское соглашение // Lamoda. Электрон. текстовые дан. - Режим доступа: https:// www.lamoda.ru/about/oferta/?from=footer (дата обращения: 30.04.2020). - Загл. с экрана.

17. Постановление Главного государственного санитарного врача Российской Федерации от 18.03.2020 № 7 «Об обеспечении режима изоляции в целях предотвращения распространения COVID2019» // Официальный интернет-портал правовой информации. - Электрон. текстовые дан. - Режим доступа: http:/publication.pravo.gov.ru/Document/ View/0001202003190001 ?index $=0 \&$ rangeSize=1 (дата обращения: 30.04.2020). - Загл. с экрана.

18. Постановление губернатора Волгоградской области от 15 марта 2020 года № 179 «О введении режима повышенной готовности функционирования органов управления, сил и средств территориальной подсистемы Волгоградской области единой государственной системы предупреждения и ликвидации чрезвычайных ситуаций» // Официальный интернет-портал правовой информации. - Электрон. текстовые дан. - Режим доступа: http:// publication.pravo.gov.ru/Document/View/ 3400202003160004 (дата обращения: 30.04.2020). Загл. с экрана.

19. Публичная оферта // Wildberries.ru - модный интернет-магазин одежды, обуви и аксессуаров. - Электрон. текстовые дан. - Режим доступа: https://www.wildberries.ru/services/publichnayaoferta?_ga=2.218553177.1714907129.15848126852096793092.1540659708 (дата обращения: 30.04.2020). Загл. с экрана.

20. Распоряжение Правительства РФ от 16.03.2020 № 635-р «О временном ограничении въезда в Российскую Федерацию иностранных граждан и лиц без гражданства и временном приостановлении оформления и выдачи виз и приглашений»- Доступ из справ.-правовой системы «КонсультантПлюс».

21. Состоялось совещание в режиме ВКС с разъяснением порядка выдачи заключений об обстоятельствах непреодолимой силы // ТПП РФ. Электрон. текстовые дан. - Режим доступа: https:// tpprf.ru/ru/news/sostoyalos-soveshchanie-v-rezhimevks-s-razyasneniem-poryadka-vydachi-zaklyucheniyob-obstoyatelstva-i351847/ (дата обращения: 30.04.2020). - Загл. с экрана.

22. Спектакль отменен // Царицынская опера. Электрон. текстовые дан. - Режим доступа: https:// tzaropera.ru/news/events/737-uvazhaemye-zriteli- 
dorogie-druzya (дата обращения: 20.03.2020). - Загл. с экрана.

23. Указ Мэра Москвы от 5 марта 2020 г. № $12-$ УМ «О введении режима повышенной готовности» // Официальный сайт мэра Москвы. - Электрон. текстовые дан. - Режим доступа: https:// www.mos.ru/upload/documents/docs/20-YM.pdf (дата обращения: 22.04.2020). - Загл. с экрана.

24. Указ Президента РФ от 17.03.2020 № 187 «О розничной торговле лекарственными препаратами для медицинского применения» // Собрание законодательства РФ. - 2020. - № 12. - Ст. 1742.

25. Услуги по выдаче сертификатов о форс-мажорных обстоятельствах стали бесплатными для бизнеса // Минэкономразвития РФ. - Электрон. текстовые дан. - Режим доступа: https://economy.gov.ru /material/news/ekonomika_bez_virusa/uslugi_po_ vydache_sertifikatov_o_fors_mazhornyh_obstoyatelstvah_ stali_besplatnymi_dlya_biznesa.html (дата обращения: 30.04 .2020$).$ - Загл. с экрана.

26. Amazon to Hire 100,000 Warehouse and Delivery Workers Amid Coronavirus Shutdowns // The Wall Street Journal. - Electronic text data. - Mode of access: https://www.wsj.com/articles/amazon-to-hire100-000-warehouse-and-delivery-workers-amidcoronavirus-shutdowns-11584387833 (date of access: 24.03.2020). - Title from screen.

27. Digital Technologies for Alternative Methods of Resolving Conflicts: The Prospects of Application in Russia and Other BRICS Countries / A. O. Inshakova, A. I. Goncharov, E. I. Inshakova, Yu. A. Tymchuk // Alternative methods of ecornomic conflicts in the national positive and soft law / ed. by A. O. Inshakova, A. V. Bogoviz. - Information Age Publishing Inc., 2020. P. $129-142$

\section{REFERENCES}

1. VOZ obyavila o nachale pandemii COVID-19 [WHO Announced the Outbreak of the COVID-19]. Vsemirnaya organizatsiya zdravoohraneniya [World Health Organization Pandemic]. URL: http:// www.euro.who.int/ru/health-topics/healthemergencies/coronavirus-covid-19/news/news/2020/ 3/who-announces-covid-19-outbreak-a-pandemic (accessed 12 March 2020).

2. Voplenko N.N. Ocherki obshchey teorii prava: monografiya [Essays of General Theory of Law. Monograph]. Volgograd, Izd-vo VolGU, 2009. 898 p.

3. Informatsiya [Information]. Onlayn-magazin Utkonos [Shop Online Duck-bill]. URL: https:// www.utkonos.ru/doc/info (accessed 20 March 2020).

4. Informatsiya dlya turistov na 14.03.2020 [Information for Tourists as of March 14, 2020]. Federalnoe agentstvo po turizmu [Federal Tourism
Agency]. URL: https://www.russiatourism.ru/news/ 16587/ (accessed 22 March 2020).

5. Inshakova A.O. Voprosy kvalifikatsii vneshneekonomicheskoy sdelki i pravovaya spetsifika nekotorykh ee vidov [Issues of Qualification of Foreign Economic Transaction and Legal Specificity of Some of Its Types]. Vestnik Volgogradskogo gosudarstvennogo universiteta. Seriya 5, Yurisprudentsiya [Journal of the Volgograd State University. Series 5. Jurisprudence], 2015, no. 2 (27),pp. 37-45.

6. Inshakova A.O., Tymchuk Yu.A. Tsifrovye tekhnologii alternativnykh metodov razresheniya sporov: zarubezhnaya praktika i perspektivy primeneniya $\mathrm{v}$ Rossii [Digital Technologies of Alternative Methods of Dispute Resolution: Foreign Practice and Prospects of Application in Russia]. Pravo i upravlenie. XXI vek [Law and Management. Twentyfirst Century], 2019, no. 1, pp. 23-31.

7. Matuzov N.I., Mal'ko A.V. Teoriya gosudarstva i prava: uchebnik [Theory of State and Law: Textbook]. Moscow, Yurist Publ., 2009. 541 p.

8. Morozova L.A. Teoriya gosudarstva i prava: uchebnik [Theory of State and Law. Textbook]. Moscow, Eksmo Publ., 2010. 480 p.

9. Muratova O.V. Kontseptsiya transnatsionalnogo potrebitelskogo prava $\mathrm{v}$ sovremennom mire [Concept of Transnational Consumer Law in the Modern World]. Lex russica, 2019, no. 7, pp. 20-28.

10. Obmen i vozvrat [Exchange and Return]. Mango. URL: https://shop.mango.com/ru/muz/help/ 2882.html (accessed 20 March 2020).

11. Onlayn-riteylery rezko narastili prodazhi produktovi uvelichili sroki dostavki [Online Retailers Have Dramatically Increased Product Sales and Increased Delivery Times]. Interfakt [Interference]. URL: https://www.interfax.ru/russia/699424 (accessed 20 April 2020).

12. OpredelenieArbitrazhnogo suda Voronezhskoy oblasti ob otkaze v udovletvorenii hodataystva ot 19.03.2020 po delu № A14-15204/2019 [Decision of the Arbitration Court of the Voronezh Region on Refusal of the Application dated 19.03.2020 in Case No. A14-15204/ 2019]. Kartoteka arbitrazhnykh del [File of Arbitration Cases] . URL: https://ras.arbitr.ru/Document/Pdf/ 0b2b08e3-036b-4c94-b7c1-ba4c2820393b/36ea22af40a9-471e-b94a-c28af4c10b67/\%D0\%9014-152042019_20200319.pdf?isAddStamp=True (accessed 10 April 2020).

13. Opredelenie Arbitrazhnogo suda Irkutskoy oblasti ob otlozhenii sudebnogo razbiratelstva ot 10.03.2020 po delu № A19-10914/2018 [Decision of the Arbitration Court of the Irkutsk Region on the Postponement of Court Proceedings dated 10.03.2020 in Case No. A19-10914/2018]. Kartoteka arbitrazhnykh del [File of Arbitration Cases]. URL: https://ras.arbitr.ru/Document/Pdf/d813d290-76ef- 
416e-b135-cd61060bb491/68363adc-c5c1-462d-bbfd308688 c fef3a/\%D 0\%9019-10914-2018 20200313.pdf?isAddStamp=True (accessed 15 April 2020).

14. Opredelenie Arbitrazhnogo suda KabardinoBalkarskoy Respubliki ot 27.03.2020 po delu № A201094/2020 [Decision of the Arbitration Court of the Kabardino-Balkan Republic dated 27.03.2020 in case No. A20-1094/2020]. Kartoteka arbitrazhnykh del [File of Arbitration Cases]. URL: http://kad.arbitr.ru/ Document/Pdf/c90277aa-0b34-4946-bccc-a1776685a09f/ fad93 f0a-e66f-41 e2-8cf0-7a8685d0cc8b/A20-10942020_20200327_Opredelenie.pdf?isAddStamp=True (accessed 26 April 2020).

15. Polozhenie o poryadke svidetelstvovaniya Torgovo-promyshlennoy palatoy Rossiyskoy Federatsii obstoyatelstv nepreodolimoy sily (forsmazhor) (prilozhenie k postanovleniyu Pravleniya TPP RF ot 23.12.2015 № 173-14) [Provision on an Order of Witnessing by Chamber of Commerce and Industry of the Russian Federation of Force Majeure Circumstances (Force Majeure) (annex to the resolution of Board of Chamber of Commerce and Industry of the Russian Federation of December 23, 2015 No. 173-14) ]. Access from Reference Legal System "KonsultantPlyus".

16. Polzovatelskoe soglashenie [User Agreement]. Lamoda. URL: https://www.lamoda.ru/ about/oferta/?from=footer (accessed 30 April 2020).

17. Postanovlenie Glavnogo gosudarstvennogo sanitarnogo vracha Rossiyskoy Federatsii ot 18.03.2020 № 7 «Ob obespechenii rezhima izolyatsii v tselyakh predotvrashcheniya rasprostraneniya COVID-2019» [Resolution of the Chief State Health Officer of the Russian Federation of March 18, 2020 No. 7 “About Providing Isolation Mode for Prevention ofDistribution ofCOVID-2019"']. Ofitsialnyy internet-portal pravovoy informatsii [Official Internet Portal of Legal Information]. URL: http://publication.pravo.gov.ru/Document/View/ 0001202003190001 ? index $=0$ \&rangeSize $=1$ (accessed 30 April 2020).

18. Postanovlenie gubernatora Volgogradskoy oblasti ot 15 marta 2020 goda № 179 «O vvedenii rezhima povyshennoy gotovnosti funktsionirovaniya organov upravleniya, sil i sredstv territorialnoy podsistemy Volgogradskoy oblasti edinoy gosudarstvennoy sistemy preduprezhdeniya i likvidatsii chrezvychaynykh situatsiy» [Resolution of the Governor of the Volgograd Region No. 179 of March 15, 2020 "On the Introduction of a Regime of High Readiness for the Functioning of the Authorities, Forces and Means of the Territorial Subsystem of the Volgograd Region of the Unified State System for Disaster Prevention and Response"]. Ofitsialnyy internet-portal pravovoy informatsii [Official Internet Portal of Legal Information]. URL: http://
publication.pravo.gov.ru/Document/View/ 3400202003160004 (accessed 30 April 2020).

19. Publichnaya oferta [The Public Offer]. Wildberries.ru - modnyy internet-magazin odezhdy, obuvi i aksessuarov [Wildberries.ru is a Trendy Online Clothing, Footwear and Accessories Store]. URL: https://www.wildberries.ru/services/publichnayaoferta?_ga=2.218553177.1714907129.15848126852096793092.1540659708 (accessed 30 April 2020).

20. Rasporyazhenie Pravitelstva RF ot 16.03.2020 № 635-r «O vremennom ogranichenii vyezda v Rossiyskuyu Federatsiyu inostrannykh grazhdan i lits bez grazhdanstva i vremennom priostanovlenii oformleniya i vydachi viz i priglasheniy») [Order of the Government of the Russian Federation No. 635-r dated 16.03.2020 “On Temporary Restriction of Entry into the Russian Federation of Foreign Citizens and Stateless Persons and Temporary Suspension of Processing and Issuance of Visas and Invitations"]. Access from Reference Legal System "KonsultantPlyus".

21. Sostoyalos soveshchanie v rezhime VKS s razyyasneniem poryadka vydachi zaklyucheniy ob obstoyatelstvakh nepreodolimoy sily [A Meeting was Held in the CCS Mode to Explain the Procedure for Issuing Opinions on the Circumstances of Force Majeure]. TPP RF [Chamber of Commerce and Industry of Russia ]. URL: https://tpprf.ru/ru/news/ sostoyalos-soveshchanie-v-rezhime-vks-srazyasneniem-poryadka-vydachi-zaklyucheniy-obobstoyatelstva-i351847/ (accessed 30 April 2020).

22. Spektakl otmenen [The Performance is Cancelled]. Tsaritsynskaya opera [Tsaritsyn Opera]. URL: https://zaropera.ru/news/events/737-uvazhaemye-zritelidorogie-druzya (accessed 20 March 2020).

23. Ukaz Mera Moskvy ot 5 marta 2020 g. № 12$\mathrm{UM}$ «O vvedenii rezhima povyshennoy gotovnosti» [The Decree of the Mayor of Moscow of March 5, 2020 No. 12-UM “About Introduction of High Alert"]. Ofitsialnyy sayt mera Moskvy [Official Site of the Mayor of Moscow]. URL: https://www.mos.ru/upload/ documents/docs/20-YM.pdf(accessed 22 April 2020 ).

24. Ukaz Prezidenta RF ot 17.03.2020 № 187 «O roznichnoy torgovle lekarstvennymi preparatami dlya meditsinskogo primeneniya» [Decree of the President of the Russian Federation No. 187 of March 17, 2020 "On Retail Trade in Medicines for Medical Use"]. Sobranie zakonodatelstva $R F$ [Collection of Legislation of the Russian Federation], 2020, no. 12, art. 1742.

25. Uslugi po vydache sertifikatov o forsmazhornykh obstoyatelstvakh stali besplatnymi dlya biznesa [Services for Issuing Certificates of Force Majeure Have Become Free for Business]. Minekonomrazvitiya $R F$ [Ministry of Economic Development of the Russian Federation]. URL: https:// economy.gov.ru/material/news/ekonomika_bez_virusa/ uslugi_po_vydache_sertifikatov_o_fors_mazhornyh_ 
obstoyatelstvah_stali_besplatnymi_dlya_biznesa.html (accessed 30 April 2020).

26. Amazon to Hire 100,000 Warehouse and Delivery Workers Amid Coronavirus Shutdowns. The Wall Street Journal. URL: https://www.wsj.com/ articles/amazon-to-hire-100-000-warehouse-anddelivery-workers-amid-coronavirus-shutdowns11584387833 (accessed 24 March 2020).
27. Inshakova A.O., Goncharov A.I., Inshakova E.I., Tymchuk Yu.A. Digital Technologies for Alternative Methods of Resolving Conflicts: The Prospects of Application in Russia and Other BRICS Countries. Inshakova A.O., Bogoviz A.V., eds. Alternative methods of ecornomic conflicts in the national positive and soft law. Information Age Publishing Inc., 2020, pp. 129-142.

\section{Information About the Author}

Yuliya A. Tymchuk, Candidate of Sciences (Jurisprudence), Assistant Lecturer, Department of Civil and International Private Law, Base Department of Southern Scientific Center of the Russian Academy of Sciences, Volgograd State University, Prosp. Universitetsky, 100, 400062 Volgograd, Russian Federation, tymchuk@volsu.ru, yuliannatymchuk@yandex.ru, https://orcid.org/0000-0002-0854-3179

\section{Информация об авторе}

Юлия Александровна Тымчук, кандидат юридических наук, ассистент кафедры гражданского и международного частного права (базовая кафедра ЮНЦ РАН), Волгоградский государственный университет, просп. Университетский, 100, 400062 г. Волгоград, Российская Федерация, tymchuk@volsu.ru, yuliannatymchuk@yandex.ru,https:/orcid.org/0000-0002-0854-3179 